\title{
Characteristics of alternating current conductivity in ternary zinc calcium phosphate glasses.
}

\begin{abstract}
Binary $(\mathrm{CaO}) \mathrm{x}(\mathrm{P} 2 \mathrm{O} 5) 1-\mathrm{x}$ glasses with mole fraction $\mathrm{x}=0.05-0.4$ with an interval of 0.05 and ternary $(\mathrm{ZnO}) \mathrm{x}(\mathrm{CaO}) 0.3-\mathrm{x}(\mathrm{P} 2 \mathrm{O} 5) 0.7$ glasses with mole fraction $\mathrm{x}=0.01-0.09$ with an interval of 0.02 were synthesized by the melt quenching technique over a wide composition range. The electrical properties of these glasses were investigated by ac impedance spectroscopy from 10 to $1 \mathrm{MHz}$ for temperatures ranging from room temperature to $300^{\circ} \mathrm{C}$. The conductivity of both samples shows dispersive behavior at lower temperatures, while at higher temperatures the conductivity is almost constant at the lower end of the frequency, approaching the dc conductivity limit and rises rapidly as the frequency is increased. We also observed that the onset of the dispersion shifted to higher frequencies with the increase in temperature. The dc conductivity ( $\sigma \mathrm{dc})$ was found to increase with higher temperatures. The activation energy for electrical conduction, $\mathrm{E} \sigma$ and activation energy for electrical relaxation, $\mathrm{E} \tau$ for $(\mathrm{ZnO}) \mathrm{x}(\mathrm{CaO}) 0.3-\mathrm{x}(\mathrm{P} 2 \mathrm{O} 5) 0.7$ were found to be slightly higher than $(\mathrm{CaO}) \mathrm{x}$ (P2O5)1-x. Observations of the dielectric strength, $\Delta \varepsilon$, of $(\mathrm{ZnO}) \times(\mathrm{CaO}) 0.3-\mathrm{x}(\mathrm{P} 2 \mathrm{O} 5) 0.7$ glasses showed that $\Delta \varepsilon$ increased with the increase of $\mathrm{ZnO}$.
\end{abstract}

Keyword: Phosphate glass; AC condductivity; Activation energy; Dielectric strength. 